\title{
AVALIAÇÃO DA DISTRIBUIÇÃO E QUALIDADE DOS CARBONATOS EM PEDOAMBIENTES DA FORMAÇÃO SOLIMÕES NO ESTADO DO ACRE
}

\author{
Dheme Rebouças de Araújo \\ Universidade Federal do Acre, Graduando em Engenharia Agronômica, \\ Cruzeiro do Sul, AC, Brasil \\ dhemebmx@gmail.com \\ Edson Alves de Araújo \\ Universidade Federal do Acre, Professor de Ciência do Solo, \\ Cruzeiro do Sul, AC, Brasil \\ earaujo.ac@gmail.com \\ Vanessa Brenda de Souza Chaves \\ Universidade Federal do Acre, Graduando em Engenharia Agronômica, \\ Cruzeiro do Sul, AC, Brasil \\ vanessa-up2011@hotmail.com \\ Alcimone Maria da Costa Silva \\ Universidade Federal do Acre, Graduando em Engenharia Agronômica, \\ Cruzeiro do Sul, AC, Brasil \\ simonyczs@hotmail.com \\ Maria Antônia da Cruz Félix \\ Universidade Federal do Acre, Graduando em Engenharia Agronômica, \\ Cruzeiro do Sul, AC, Brasil \\ cfceng@hotmail.com \\ Meiriane de Sousa Brito \\ Universidade Federal do Acre, Graduando em Engenharia Agronômica, \\ Cruzeiro do Sul, AC, Brasil \\ meirianeczs@hotmail.com
}

\section{RESUMO}

O presente estudo tem como objetivos caracterizar, espacializar e avaliar qualidade física e química de amostras de carbonato para uso como corretivo agrícola, coletadas ao longo da BR 364 entre os municípios de Cruzeiro do Sul e Sena Madureira, Acre. A identificação preliminar dos locais de ocorrência dos carbonatos foi feita por meio do exame dos cortes de estrada e a averiguação com a utilização de $\mathrm{HCl}$ a $10 \%$. Foram identificados e georreferenciados 122 locais com a ocorrência de carbonatos. As análises foram realizadas conforme preconiza o Ministério da Agricultura, Pecuária e Abastecimento, e consistiram na determinação da reatividade (RE), Poder de Neutralização (PN), dos percentuais de CaO e $\mathrm{MgO}$ e do Poder Relativo de Neutralização Total (PRNT). Os resultados obtidos através da $\mathrm{RE}$ apresentaram características favoráveis ao uso agrícola. Os valores de $\% \mathrm{CaO}+\% \mathrm{MgO}$, PN e PRNT de determinadas amostras não se enquadraram nos mínimos exigidos pelo MAPA $(\% \mathrm{CaO}+\% \mathrm{MgO}=38 \% ; \mathrm{PN}=67 \%$ e PRNT $=45 \%)$. Em geral foram constatados valores elevados de RE (73,11 a $87,31 \%$ ) e baixos valores de PN (40 a $75 \%$ ) e PRNT $(30,59$ a $62,46 \%)$, o que inviabiliza sua utilização em escala industrial. No entanto não se descarta sua utilização por agricultores familiares da região.

Palavras-chave: Acidez. Calcário. Pedogênese.

\section{EVALUATION OF THE DISTRIBUTION AND QUALITY OF CARBONATES IN PEDOENVIRONMENTS OF THE SOLIMÕES FORMATION IN THE STATE OF ACRE}

\section{ABSTRACT}

The present study aims to characterize, spatialize and evaluate the physical and chemical quality of carbonate material to use as soil liming and collected along the BR 364 Highway, specifically located between the municipalities of Cruzeiro do Sul and Sena Madureira, Acre. The preliminary identification of the carbonate occurrence sites was made through the examination of the road cuts and the investigation with the use of $10 \% \mathrm{HCl}$. In total, 122 
Avaliação da distribuição e qualidade dos carbonatos em pedoambientes da formação Solimões no estado do Acre
Dheme Rebouças de Araújo; Edson Alves de Araújo; Vanessa Brenda de Souza Chaves; Alcimone Maria da Costa Silva; Maria Antônia da Cruz Félix Meiriane de Sousa Brito

\begin{abstract}
sites were identified and georeferenced with the occurrence of carbonates and from this total 18 sites were selected for sampling. The analyzes were carried out as recommended by the Ministry of Agriculture and Food Supplies, and consisted of determining the reactivity rate (RR), neutralization power (NP), $\mathrm{CaO}$ and $\mathrm{MgO}$ percentages, and relative efficiency of reactivity (RER). The values of $\% \mathrm{CaO}+\% \mathrm{MgO}, \mathrm{NP}$ and RER of certain samples did not meet the minimum required by MAPA $(\% \mathrm{CaO}+\% \mathrm{MgO}=38 \%, \mathrm{NP}=67 \%$ and $\mathrm{RER}=$ $45 \%)$. In general, high values of RR (73.11 to $87.31 \%$ ) and low values of NP (40 to $75 \%$ ) and RER (30.59 to $62.46 \%$ ) were found, which made it impossible to use them on an industrial scale. However, their use by family farmers in the region is not ruled out.
\end{abstract}

KeyWords: Acidity. Limestone. Pedogenesis.

\title{
INTRODUÇÃO
}

Os solos do Acre são caracterizados como de origem sedimentar, esses se constituíram das deposições ocorrentes ao longo de várias eras, onde estão presentes diversas formações geológicas. Entre as várias coberturas geológicas, que recobrem o território Acreano, destaca-se a Formação Solimões, depositada no fim do Mioceno e o início do Plioceno, sendo a mais extensa das unidades litoestratigráficas do estado, estendendo-se além da fronteira para os territórios peruano e boliviano (CAVALCANTE, 2010).

A Formação Solimões apresenta várias litologias, na sua maior parte argilitos com concreções carbonáticas e gipsiferas, ocasionalmente com material carbonizado (turfo e linhito), concentrações esparsas de pirita e grande quantidade de fosseis de vertebrados e invertebrados (AMARAL et al., 2013).

A intensa ação erosiva nas rochas andinas foi responsável pelo imenso volume de sedimentos presente na Formação Solimões, carreados pelas drenagens e que foram se depositando no fundo de lagos, constituindo finas camadas de argilitos, carbonato de cálcio e areia (CAJAZEIRAS et al., 2015).

As ocorrências de depósitos de gipsita $\left(\mathrm{CaSO}_{4} 2 \mathrm{H}_{2} \mathrm{O}\right)$ e concreções carbonáticas $\left(\mathrm{CaCO}_{3}\right)$ presentes no pedoambiente da Formação Solimões não é comum em condições de clima tropical úmido, no qual o estado do Acre apresenta atualmente. Esses materiais, por sua vez, segundo Kronberg e Benchimol $(1992,1993)$ são de ocorrência somente em regiões de climas áridos em razão da evaporação de águas ricas em sulfatos e carbonatos.

Estudos conduzido por Schaefer (2013) evidenciam que durante o período do Pleistoceno (aproximadamente 11.500 anos passados), ambientes semiáridos com elevada evapotranspiração e secas severas predominaram na região Amazônica Ocidental, condicionando uma evaporação intensa de águas ricas em sulfato e carbonato suficiente para formação de evaporitos. Lani e Amaral (2002) destacam que atualmente esses materiais encontram-se distribuídos na região em forma de veios e níveis de carbonato de cálcio e sulfato de cálcio.

A variedade litológica da Formação Solimões, combinada com a ação do clima atual e pretérito, condiciona, por sua vez, uma grande diversidade de solos e relevo associados (pedoambiente) (BARDALES et al., 2010). Essa diversidade de ambiente proporciona a ocorrência de solos com uma juventude inesperada e um grau de intemperismo pouco acentuado (SCHAEFER, 2013), que os diferenciam das demais classes de solos que ocorrem em outras regiões do país (WARD, 2002).

\section{CORRETIVO AGRÍCOLA}

Ultimamente as rochas carbonáticas moídas compostas dos minerais calcita $\left(\mathrm{CaCO}_{3}\right)$, dolomita $\left(\mathrm{CaMg}\left(\mathrm{CO}_{3}\right)_{2}\right)$ e magnesita $\left(\mathrm{MgCO}_{3}\right)$, apresentam uma grande variedade de usos, desde matéria prima para a construção civil até sua utilização na agricultura como corretivos (calcário) de solos ácidos. 
Avaliação da distribuição e qualidade dos carbonatos em pedoambientes da formação Solimões no estado do Acre
Dheme Rebouças de Araújo; Edson Alves de Araújo; Vanessa Brenda de Souza Chaves; Alcimone Maria da Costa Silva; Maria Antônia da Cruz Félix Meiriane de Sousa Brito

De acordo com Mello Filho (2005), para o calcário ser considerado como corretivo de solos, deve ter como limites mínimos $38 \%$ para a soma $\mathrm{CaO}+\mathrm{MgO}$. Contudo, o mercado agrícola é mais exigente em relação às características químicas do calcário, preferindo os corretivos de solo que apresentam no mínimo 10\% MgO, soma de \% CaO e \% MgO mínima de 48\% (VIDAL et al., 2008).

O Ministério da Agricultura, Pecuária e Abastecimento (MAPA) estabelece quatro faixas de PRNT para efeito de classificação e comercialização de calcário (KOCHE et al., 1989): Faixa A: com PRNT entre 45,0 e 60,0\%; Faixa B: com PRNT entre 60,1 e 75,0\%; Faixa C: com PRNT entre 75,1 e 90\%; Faixa D: com PRNT maior que $90 \%$.

A grande distância dos centros produtores de adubos e corretivos encarece o preço de insumos no estado do Acre (QUEIROZ et al., 2015), onerado a aquisição dos mesmos para o uso, considerando agricultura familiar. Por isso, uma alternativa de obtenção do calcário, dentro do estado, além de proporcionar um custo de transporte menor ainda possibilita uma maior aquisição por agricultores familiares da região.

Nesse contexto, o presente estudo tem como objetivos caracterizar, espacializar e avaliar a qualidade física e química (pureza) de amostras de carbonato para avaliação de seu uso como corretivo agrícola, coletadas ao longo da BR 364 entre os municípios de Cruzeiro do Sul e Sena Madureira, Acre, de maneira a contribuir para o uso deste insumo no estado e assim proporcionar melhor qualidade do solo para uso agrícola.

\section{METODOLOGIA}

\section{CARACTERÍSTICAS GERAIS DA ÁREA DE ESTUDO}

A área de estudo consistiu no trecho ao longo da BR 364, entre os municípios de Cruzeiro do Sul (070

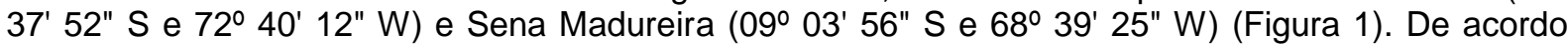
com a classificação de Köppen, o clima da região é classificado como tropical úmido, com chuvas bem distribuídas ao longo do ano e temperatura mínima $20,4^{\circ}$ e máxima $31,7^{\circ} \mathrm{C}$ (ACRE, 2006).

Figura 1: Mapa de localização da área de estudo. Mapa do Brasil, destacando o Estado do Acre e a área de estudo nos mapas dos municípios de Cruzeiro do Sul, Tarauacá, Feijó, Manuel Urbano e Sena Madureira.

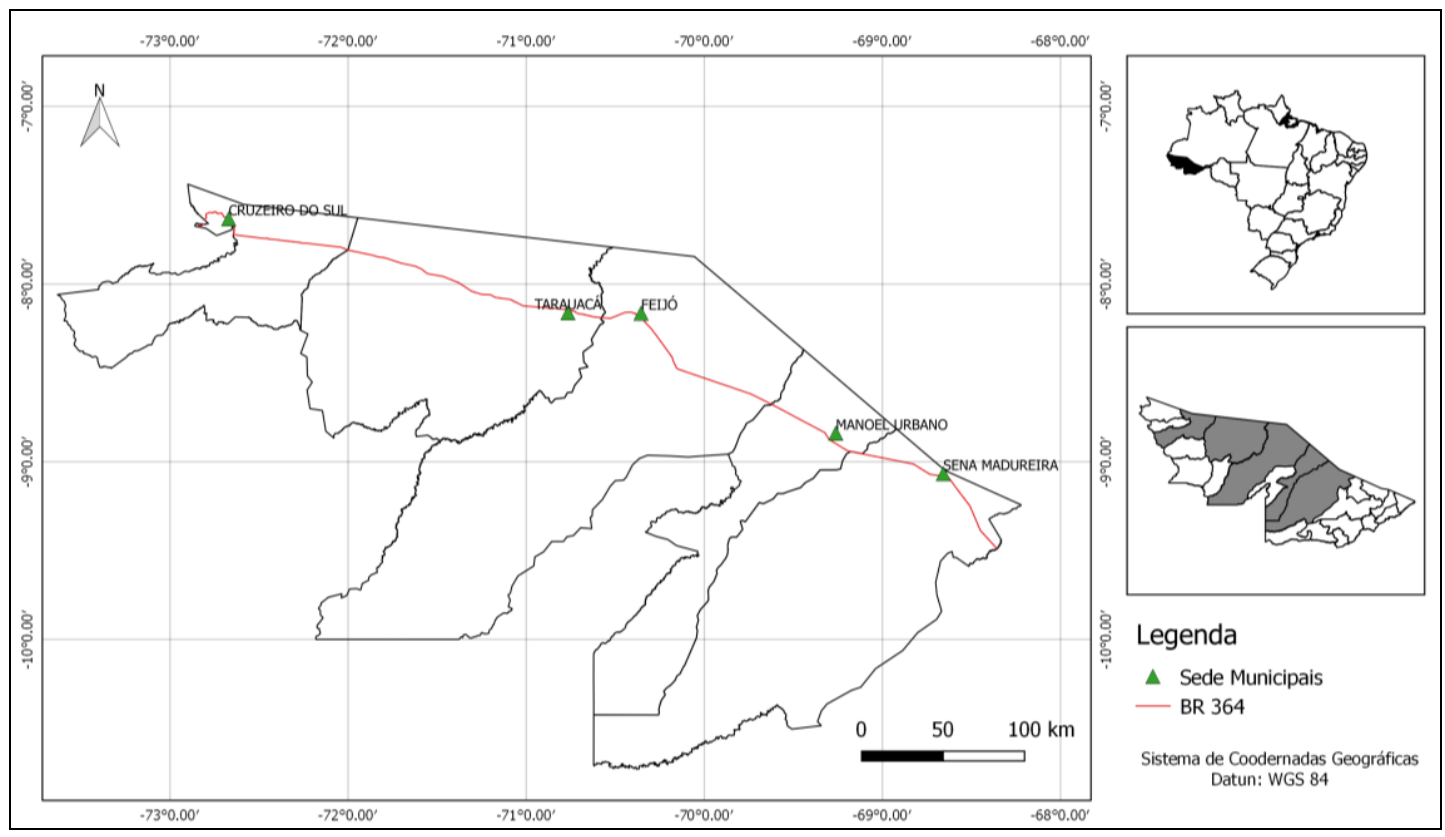

Fonte: Dados da pesquisa. 
Avaliação da distribuição e qualidade dos carbonatos em pedoambientes da formação Solimões no estado do Acre
Dheme Rebouças de Araújo; Edson Alves de Araújo; Vanessa Brenda de Souza Chaves; Alcimone Maria da Costa Silva; Maria Antônia da Cruz Félix Meiriane de Sousa Brito

A unidade geomorfológica compreende a Depressão do Juruá-laco que compõe a unidade morfoestrutural da Depressão Amazônica, caracterizada por uma feição colinosa e relevo ondulado. No tocante a geologia, a Formação Solimões recobre toda área estudada, está originada de rochas sedimentares, formadas principalmente por arenitos, siltitos e argilitos de origem continental (CAVALCANTE, 2010).

As classes predominantes de solos da área de estudo estão descritas no Zoneamento EcológicoEconômico do Acre (ACRE, 2006), que vão desde a ocorrência de Luvissolos e Cambissolos apresentando argila de atividade alta $(\mathrm{Ta})$, até Vertissolos, pouco profundo com baixa permeabilidade.

\section{COLETA DO MATERIAL CARBONÁTICO E ESPACIALIZAÇÃO DOS LOCAIS DE OCORRÊNCIA}

A área de coleta do material carbonático se deu ao longo da BR-364, no trecho entre os municípios de Cruzeiro do Sul e Sena Madureira. A identificação dos carbonatos foi realizada inicialmente por meio do exame (visual) dos cortes de estrada, e em seguida procedia-se a escarificação do material e efetuava-se teste com Ácido Clorídrico $(\mathrm{HCl})$ a 10\% conforme recomenda o Manual de Descrição e Coleta de Solo no Campo (SANTOS et al., 2015).

Distribuídas ao longo de todo o percurso foram realizadas 18 coletas de amostras de material carbonático. Para a seleção dos pontos de coleta levou-se em consideração o relevo (áreas planas, onduladas ou suave onduladas), vegetação (área florestada ou com pastagens) hidrografia (próximo ou distante dos rios) e o conteúdo pedológico (classes de solos de ocorrência ao longo do trajeto) no qual os materiais carbonáticos estavam inseridos.

No geral, tentou-se abranger a regional do Purus (Sena Madureira e Manoel Urbano), área com predomínio de solos com argila de atividade alta (Ta) e ocorrência de gipsita; Regional do Tarauacá e Envira (Feijó e Tarauacá) situada na parte central do estado, tendo como característica o relevo ondulado a forte ondulado, e a Regional do Juruá (Cruzeiro do Sul), caracterizada pela ocorrência de solos arenosos de baixa fertilidade.

As regionais são regiões de desenvolvimentos propostas pelo governo do Estado do Acre com o objetivo de sistematizar a administração (AMARAL, 2000). Atualmente o Acre encontra-se dividido em cinco regionais (Regional do Juruá, Regional do Alto Acre, Regional do Baixo Acre, Regional do Tarauacá e Envira e Regional do Purus).

Concomitantemente fez-se uso de um sensor GPS (GPSmap 76csx da Garmim) navegação de modo a georreferenciar os sítios de ocorrência do material carbonático. $E$ através do software de sistema de informações geográficas (SIG) Qgis (QGIS Equipe de desenvolvimento, 2016) versão 2.12.3-Lyon, procedeu-se a espacialização e geração de mapa temático qualitativo (mapa de ocorrência de material carbonático ao longo da BR-364, sentido Cruzeiro do Sul a Sena Madureira, Acre).

\section{DETERMINAÇÕES ANALÍTICAS}

As amostras coletadas a campo foram lavadas com água destilada e postas para secar em ambiente sombreado e ventilado para posteriormente ser realizada sua maceração. A quebra do material foi feita sobre uma chapa de alumínio liso utilizando uma marreta tipo oitava de $2 \mathrm{~kg}$ para em seguida ser determinada a composição granulométrica.

A caracterização das amostras quanto a sua granulometria (Reatividade-RE) procedeu-se mediante a porcentagem de partículas retidas nas peneiras ABNT no $10(2 \mathrm{~mm})$, ABNT no $20(0,84 \mathrm{~mm})$, ABNT no $50(0,30 \mathrm{~mm})$ e fundo $(<0,30 \mathrm{~mm})$, através de um agitador mecânico de peneira da Produtest modelo $T$. Nesse procedimento as peneiras foram empilhadas sobre o agitador na ordem da menor malha $(0,30 \mathrm{~mm})$ para a maior malha $(2 \mathrm{~mm})$, sendo que, abaixo da peneira de menor malha $(0,30 \mathrm{~mm})$ foi colocado o fundo de peneiras.

Em seguida foi adicionado $100 \mathrm{~g}$ de carbonato macerado sobre a peneira de maior malha $(2 \mathrm{~mm}) \mathrm{e}$ ligado o agitador durante um período de 5 minutos. Após esse tempo pesou-se a quantidade de calcário retido em cada peneira e a que passou pela última e calculou a RE conforme formula abaixo: 


$$
R E=\frac{(\mathrm{F} 1 \times 0)+(\mathrm{F} 2 \times 20)+(\mathrm{F} 3 \times 60)+(\mathrm{F} 4 \times 100)}{100}
$$

Sendo: $F 1=$ percentagem de produto retido na peneira ABNT № $10(2 \mathrm{~mm}) ; \mathrm{F} 2=$ percentagem de produto retido na peneira ABNT № $20(0,84 \mathrm{~mm})$; $\mathrm{F} 3=$ percentagem de produto retido na peneira ABNT № $50(0,30 \mathrm{~mm})$; F4= percentagem de produto passado na peneira ABNT № $50(0,30 \mathrm{~mm})$.

Após a separação das frações granulométrica, os corretivos foram submetidos a determinação do poder neutralizante (PN) pelo método da titulação ácido-base, seguindo o procedimento do Ministério da Agricultura, Pecuária e Abastecimento (BRASIL, 2014) descrito abaixo.

Utilizando uma balança analítica, pesou-se $1 \mathrm{~g}$ de carbonato e transferiu-se esse material para erlenmeyer de $250 \mathrm{~mL}$ e adicionou-se $25 \mathrm{~mL}$ de $\mathrm{HCl} 1 \mathrm{~mol} \mathrm{~L}$ padronizado (VA). Em outro erlenmeyer foi adicionado $25 \mathrm{~mL}$ do $\mathrm{HCl} 1 \mathrm{~mol} \mathrm{~L}$ formando a prova em branco (VB). Foi aquecido os erlenmeyers em chapa quente e colocados para ferver por 5 minutos, após esse tempo foi retirado da chapa e deixado esfriar. Posteriormente a solução foi transferida para balão de $100 \mathrm{~mL}$ que teve seu volume completado com água destilada e deixado decantar. Pipetou-se $50 \mathrm{~mL}$ da solução que foi transferida para elenmeyer de $125 \mathrm{~mL}$, no qual se acrescentou três gotas de solução de fenolftaleína e titulou-se com a solução padrão de $\mathrm{NaOH} 1 \mathrm{~mol} \mathrm{~L}$, até o aparecimento de uma leve cor rosada do indicador. Como foi feito em duplicata as amostras de (VA) calculou-se a média aritmética dos volumes de $\mathrm{NaOH}$ gastos na titulação. Para a prova em branco (VB), que foi feito sem duplicata, foi anotado apenas o volume de $\mathrm{NaOH}$ gastos. A partir desses valores calculou-se o PN e por fim o PRNT do calcário utilizando o procedimento padrão (BRASIL, 2014).

\section{RESULTADOS E DISCUSSÃO}

Durante o trajeto compreendido foram identificados e georreferenciados 122 locais com incidência de carbonatos (Figura 2). Estes, em sua maioria, apresentavam-se na forma de pequenas concreções presentes no horizonte $\mathrm{C}$ dos solos (Figura 3 ).

Figura 2: Mapa com os locais de ocorrência de material carbonático ao longo da BR-364, sentido Cruzeiro do Sul a Sena Madureira, Acre.

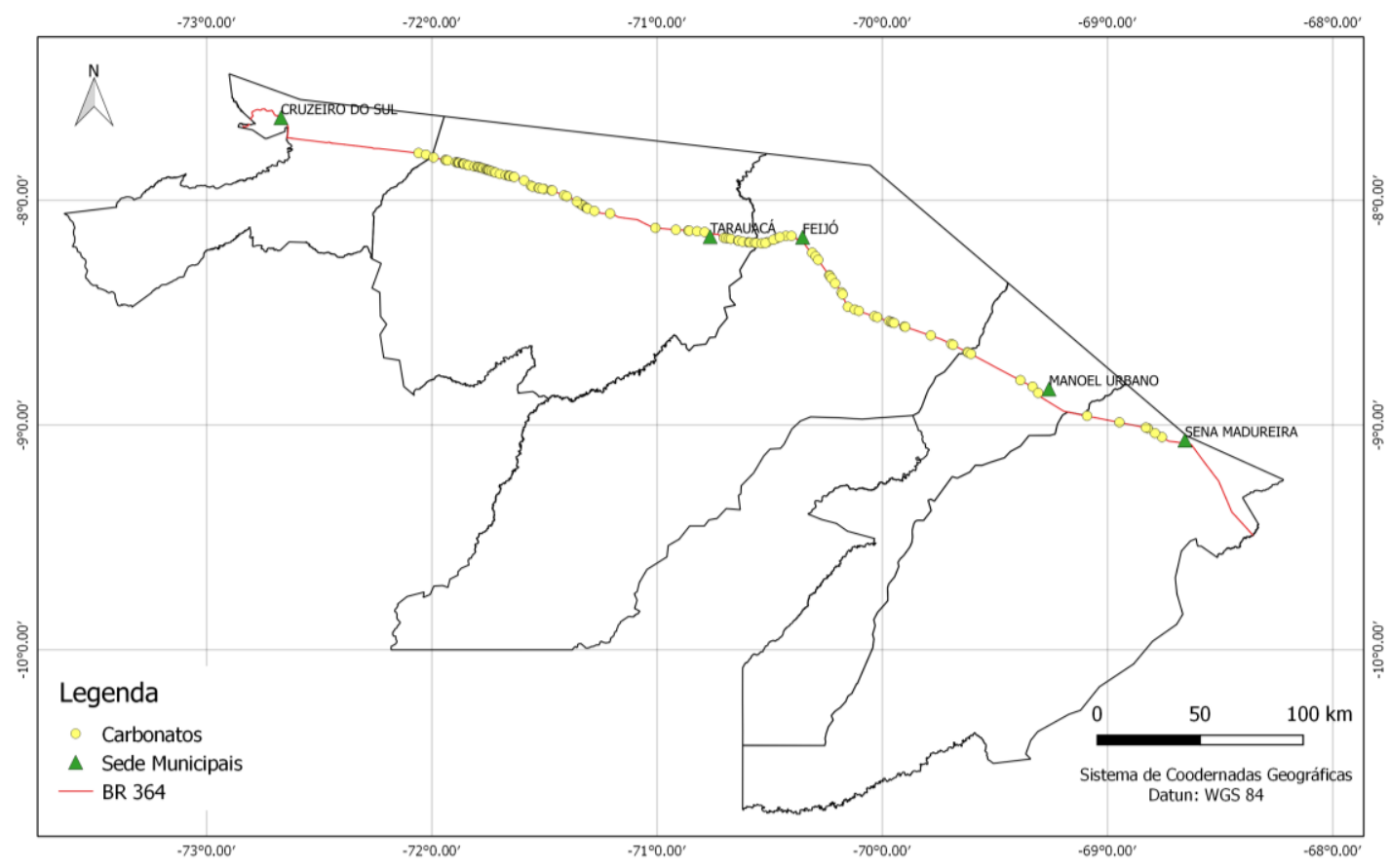

Fonte: Dados da pesquisa 
Avaliação da distribuição e qualidade dos carbonatos em pedoambientes da formação Solimões no estado do Acre
Dheme Rebouças de Araújo; Edson Alves de Araújo; Vanessa Brenda de Souza Chaves; Alcimone Maria da Costa Silva; Maria Antônia da Cruz Félix Meiriane de Sousa Brito

Figura 3: Formas de ocorrências do material carbonático. (a e b) Concreções no horizonte $\mathrm{C}$ do solo; (c) paredão formado por um maciço rochoso; (d) bancada.

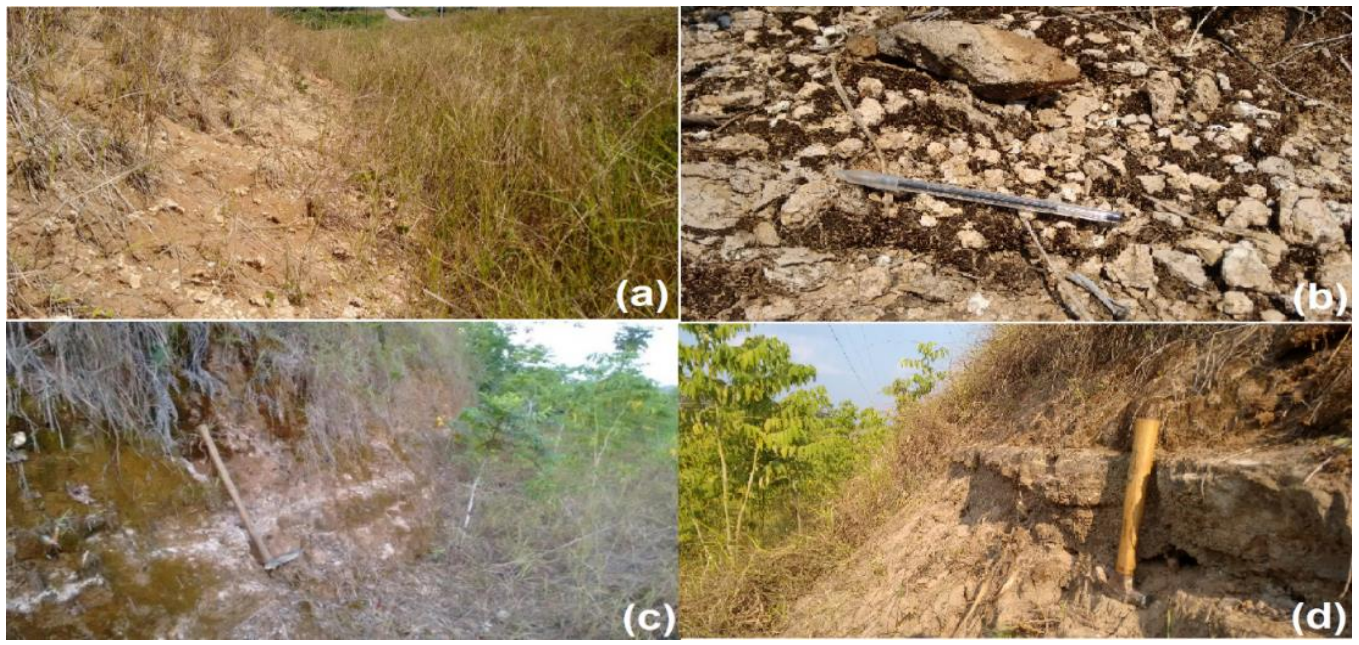

Foto: Dheme Araújo, 2015.

O clima tropical úmido que o estado do Acre apresenta atualmente fez com que o material oriundo da evaporação intensa de águas ricas em sulfatos e carbonatos fossem submetidos a processos intempéricos, resultando na dissolução dos seus componentes minerais. Estudos de Cunha et al. (2014) ressaltam que as condições de restrições de drenagem, resultantes das características ambientais e da granulometria fina dos sedimentos originais da Formação Solimões, condicionam um processo de intemperismo menos intenso aos solos do Acre.

Em decorrência da natureza do material sedimentar clástico, essencialmente pelíticos da Formação Solimões a qual os carbonatos encontram-se envolvido, a atuação do intemperismo químico aconteceu de forma menos intensa, possibilitando com que esses materiais ainda sejam observados nos dias atuais ao longo dos cortes de estrada e nos barrancos de rios e igarapés.

Carbonato em forma de paredão e bancadas foram observados ao longo do trajeto. O paredão carbonático formado por um maciço rochoso apresenta-se recoberto por um material argiloso com cores brunadas (marrom). O local desta ocorrência caracteriza-se por apresentar relevo suave ondulado, coberto por vegetação secundária e plantas conhecidas na região como a pimenta longa (Piper hispidinervum), embaúba (Cecropia sp) e malícia ou sensitiva (Mimosa pudica).

A ocorrência de material carbonático, no trecho entre Cruzeiro do Sul e Sena Madureira, acontece de forma esparsa e envolto pelo solo, o que gera em sua exploração uma quantidade enorme de rejeitos. A ocorrência de depósitos pouco expressivos pode ser o motivo do baixo interesse pelos carbonatos na região, o que explica a falta de estudos para sua exploração nos anos anteriores.

Os resultados obtidos para a reatividade (RE) através da análise granulométrica (Tabela 1) obtiveram uma média de $78,9 \%$ o que demonstra a existência de amostras com granulometria bastante fina em destaque tem-se a amostra número 10, coletada no município de Feijó que apresentou valor máximo $(87,31 \%)$.

Os valores de RE presentes na Tabela 1, apresentaram variação de 6,89\%, demostrando não haver uma variação distante entre valores em relação ao valor da média aritméticas, comprovando com isso, valores de RE bem homogêneos.

A partir dos resultados, observa-se que todas as amostras avaliadas apresentam valores de RE bastante promissores (Tabela 1), isso demostra que o calcário terá uma maior reatividade pelo solo por apresentar partículas bastante pequenas (maior superfície específica). 
Tabela 1: Valores das partículas retidas e passadas em diferentes peneiras e a reatividade (RE) de 18 amostras de carbonato coletadas ao longo da BR 364 entre Cruzeiro do Sul e Sena Madureira, Acre.

\begin{tabular}{|c|c|c|c|c|c|c|}
\hline \multirow[t]{2}{*}{$\begin{array}{l}\text { Município de } \\
\text { Ocorrência }\end{array}$} & \multirow[t]{2}{*}{ Amostras } & \multicolumn{3}{|c|}{$\begin{array}{c}\text { Valores Retidos em } \\
\text { Peneira ABNT № }\end{array}$} & \multirow{2}{*}{$\begin{array}{c}\begin{array}{c}\text { Valores Passados em } \\
\text { Peneiras ABNT № }\end{array} \\
50 \\
(0,30 \mathrm{~mm}) \\
\end{array}$} & \multirow{2}{*}{ RE } \\
\hline & & $\begin{array}{c}10 \\
(2 \mathrm{~mm}) \\
\end{array}$ & $\begin{array}{c}20 \\
(0,84 \mathrm{~mm}) \\
\end{array}$ & $\begin{array}{c}50 \\
(0,30 \mathrm{~mm}) \\
\end{array}$ & & \\
\hline Cruzeiro do Sul & 1 & 0,53 & 6,9 & 34,95 & 56,83 & 79,18 \\
\hline Cruzeiro do Sul & 2 & 0,21 & 11,71 & 34,35 & 53,16 & 76,11 \\
\hline Tarauacá & 3 & 0,5 & 11,88 & 33,73 & 53,55 & 76,16 \\
\hline Tarauacá & 4 & 0,12 & 3,92 & 32,38 & 63,07 & 83,28 \\
\hline Tarauacá & 5 & 0,1 & 6,36 & 34,41 & 58,64 & 80,56 \\
\hline Tarauacá & 6 & 0 & 7,2 & 38,61 & 53,41 & 78,02 \\
\hline Tarauacá & 7 & 0,17 & 9,2 & 33,98 & 56,18 & 78,41 \\
\hline Tarauacá & 8 & 0,18 & 7,17 & 21,02 & 71,19 & 85,24 \\
\hline Feijó & 9 & 0,06 & 11,21 & 43,3 & 44,89 & 73,11 \\
\hline Feijó & 10 & 0,3 & 7,07 & 22,88 & 72,17 & 87,31 \\
\hline Feijó & 11 & 0,49 & 7,36 & 23,61 & 67,93 & 83,57 \\
\hline Feijó & 12 & 0 & 0,4 & 41,4 & 57,64 & 82,56 \\
\hline Feijó & 13 & 0,25 & 8,19 & 30,31 & 60,75 & 80,57 \\
\hline Sena Madureira & 14 & 0 & 4,04 & 42,72 & 52,72 & 79,16 \\
\hline Sena Madureira & 15 & 0,23 & 10,31 & 40,79 & 48,23 & 74,77 \\
\hline Sena Madureira & 16 & 0,2 & 7,53 & 40,7 & 51,31 & 77,24 \\
\hline \multirow{2}{*}{$\begin{array}{c}\text { Manoel Urbano } \\
\text { Feijó }\end{array}$} & 17 & 0 & 3,65 & 41,77 & 54,82 & 80,61 \\
\hline & 18 & 0,02 & 6,71 & 32,4 & 60,39 & 81,17 \\
\hline Feijó & & \multicolumn{4}{|c|}{ Valor Máximo } & 87,31 \\
\hline \multirow{3}{*}{\multicolumn{2}{|c|}{ Total }} & \multicolumn{4}{|c|}{ Valor Mínimo } & 73,11 \\
\hline & & \multicolumn{4}{|c|}{ Média Aritmética } & 78,9 \\
\hline & & \multicolumn{4}{|c|}{ Coeficiente de Variação } & 6,89 \\
\hline
\end{tabular}

De acordo com Koche et al. (1989), os calcários (obtido pela moagem de rocha calcária) devem possuir as seguintes características: passar 100\% em peneira de $2 \mathrm{~mm}$ (ABNT 10), 70\% em peneira $0,84 \mathrm{~mm}$ (ABNT 20) e $50 \%$ em peneira de $0,30 \mathrm{~mm}$ (ABNT 50), com tolerância de $5 \%$ na peneira ABNT 10. Pelos resultados contidos na (Tabela 1), apenas as amostras 9 e 15 não obtiveram os valores percentuais de $50 \%$ de calcário passante em peneiras de $0,30 \mathrm{~mm}$. Os demais ficaram de acordo com a legislação, tendo mais de $50 \%$ de suas partículas passadas na peneira de $0,30 \mathrm{~mm}$ e, com isso, apresentado reatividade de $100 \%$ para essas frações.

A reatividade expressa a granulometria do corretivo que consiste em sua velocidade de ação quando em contato com o solo, isto é, a rapidez em que a acidez pode ser corrigida (DEUS, 2010). O tamanho das partículas condiciona a taxa de reatividade do calcário, uma vez que a velocidade de neutralização depende da área superficial do corretivo em contato com o solo (RODRIGHERO et al., 2015). 
Avaliação da distribuição e qualidade dos carbonatos em pedoambientes da formação Solimões no estado do Acre
Dheme Rebouças de Araújo; Edson Alves de Araújo; Vanessa Brenda de Souza Chaves; Alcimone Maria da Costa Silva; Maria Antônia da Cruz Félix Meiriane de Sousa Brito

$\mathrm{Na}$ análise química que se obtiveram os valores do poder neutralizante (PN) (Tabela 2), que é a capacidade de correção da acidez do solo do calcário, foi apresentado uma média de $62,5 \%$. As amostras quatro, em Tarauacá, 13 em Sena Madureira e 14, em Feijó, apresentaram valor máximo de PN (75\%). Valor mínimo (40\%) foram encontrados nas amostras 10 e 11 correspondentes ao município de Feijó. Essa variação de valores de PN demostram que cada amostra de carbonato avaliada tem uma determinada capacidade de neutralização da acidez dos solos.

Tabela 2: Caracterização química, poder de neutralização (PN) e poder relativo de neutralização total (PRNT) de 18 amostras de carbonato coletadas ao longo da BR 364 entre os municípios de Cruzeiro do Sul e Sena Madureira, Acre.

\begin{tabular}{|c|c|c|c|c|c|c|}
\hline $\begin{array}{c}\text { Município de } \\
\text { Ocorrência }\end{array}$ & Amostras & $\mathrm{CaO}$ & $\mathrm{MgO}$ & $\mathrm{CaO}+\mathrm{MgO}$ & PN & PRNT \\
\hline Cruzeiro do Sul & 1 & 24,92 & 8,50 & 33,42 & 50 & 30,59 \\
\hline Cruzeiro do Sul & 2 & 31,00 & 11,50 & 42,50 & 70 & 53,27 \\
\hline Tarauacá & 3 & 32,06 & 7,25 & 39,31 & 70 & 53,31 \\
\hline Tarauacá & 4 & 33,96 & 8,75 & 42,71 & 75 & 62,46 \\
\hline Tarauacá & 5 & 27,24 & 8,00 & 35,24 & 55 & 44,3 \\
\hline Tarauacá & 6 & 54,56 & 19,50 & 74,06 & 55 & 42,9 \\
\hline Tarauacá & 7 & 38,67 & 13,25 & 51,92 & 70 & 54,88 \\
\hline Tarauacá & 8 & 39,65 & 5,50 & 45,15 & 70 & 59,66 \\
\hline Feijó & 9 & 30,07 & 10,50 & 40,75 & 70 & 51,17 \\
\hline Feijó & 10 & 18,21 & 5,75 & 23,96 & 40 & 34,92 \\
\hline Feijó & 11 & 17,47 & 7,75 & 25,22 & 40 & 34,92 \\
\hline Feijó & 12 & 31,51 & 10,25 & 41,76 & 70 & 57,79 \\
\hline Feijó & 13 & 35,50 & 13,00 & 48,50 & 75 & 60,43 \\
\hline Sena Madureira & 14 & 34,92 & 7,00 & 41,92 & 75 & 59,37 \\
\hline Sena Madureira & 15 & 32,20 & 6,25 & 38,45 & 70 & 52,33 \\
\hline Sena Madureira & 16 & 32,69 & 8,50 & 41,19 & 65 & 50,19 \\
\hline Manoel Urbano & 17 & 26,75 & 8,50 & 35,25 & 55 & 44,33 \\
\hline Feijó & 18 & 26,00 & 6,75 & 32,75 & 50 & 40,58 \\
\hline \multirow{4}{*}{ Total } & \multicolumn{2}{|c|}{ Valor Máximo } & 19,5 & 74,06 & 75 & 62,46 \\
\hline & \multicolumn{2}{|c|}{ Valor Mínimo } & 5,5 & 23,96 & 40 & 30,59 \\
\hline & \multirow{2}{*}{\multicolumn{2}{|c|}{$\begin{array}{c}\text { Média Aritmética } \\
\text { Coeficiente de Variação }\end{array}$}} & 9,25 & 40,77 & 62,5 & 49,22 \\
\hline & & & 37 & 26,82 & 18,86 & 19,99 \\
\hline
\end{tabular}

Os resultados expressos pelo coeficiente de variação do PN (18,86\%) e PRNT (19,89\%) demonstram que os valores encontrados apresentam-se de naturezas semelhante em relação à média dos valores (PN 62,5\% e PRNT 49,22) o que demostra haver uma homogeneidade entre valores tanto pra PN como para PRNT.

As variações de PN mostradas na (Tabela 2), segundo Maeda et al. (1996) é atribuída à natureza (química e mineralógica) e proporção dos componentes do calcário. Segundo Koche et al. (1989), os calcários devem apresentar, no mínimo, PN equivalente a 67\%, soma dos teores de óxidos de cálcio e magnésio (\%CaO + \%MgO) de $38 \%$ e PRNT de $45 \%$.

Em consideração a soma dos teores de óxidos de cálcio e magnésio as amostras um, cinco, 10,11, 17 e 18 tiveram esses teores abaixo do mínimo exigidos pela legislação (38\%). As demais obtiveram a soma de óxidos de cálcio e magnésio acimas do valor mínimo sugerido, apresentando-se condizentes com a legislação vigente.

Os calcários são classificados de acordo com sua concentração de $\mathrm{MgO}$ como magnesiano (5 a 12\%), dolomíticos (acima de 12\%), ou calcíticos (menor que 5\%) (PRIMAVESI, 2004). Em relação a porcentagem de óxido de magnésio as amostras seis, sete e 13 estão enquadradas como calcários 
dolomíticos (\%MgO acima de 12\%), as demais enquadram-se na classe de calcários magnesiano (\%MgO de cinco a $12 \%)$.

De acordo com o valor de PN, as amostras números um, cinco, seis, 10, 11, 16, 17 e 18 são calcários que estão com valores abaixo do valor mínimo exigido (menos de $67 \%$ de PN). Esses valores baixos fazem com que menor seja a quantidade de ácidos que o calcário neutraliza no solo. Já as demais amostras de calcários estão com PN acima da mínima exigida (maior que 67\%), o que proporcionar maior quantidade de ácidos neutralizada.

Os valores de PRNT (Tabela 2) apresentaram média de 49,22\%, na qual a amostra quatro, no município de Tarauacá, apresentou valor máximo $(62,46 \%)$ e a amostra de número um pertencente ao município de Cruzeiro do Sul obteve valor mínimo (30,59\%).

As amostras um, cinco, seis, 10,11, 17 e 18 não obtiveram os valores mínimos de PRNT (45\%), isso implica na qualidade final do calcário como corretivo da acidez do solo, pois, calcários com PRNT menor que $45,0 \%$ não podem ser comercializados.

Já as amostras dois, três, sete, oito, nove, $12,14,15$ e 16 se enquadraram na classe de faixa $A$ com PRNT entre 45,0 e $60,0 \%$. O restante das amostras (quatro e 13) se enquadraram na Faixa B: com PRNT entre 60,1 e 75,0\%. Desse modo, quanto maior o PRNT, menor o tempo de reação no solo, permitindo que seja aplicado com menos antecedência (NAHASS e SEVERINO, 2003).

\section{CONCLUSÃO}

Os resultados apontam evidências para concluir que as frações granulométricas mostraram-se eficientes, uma vez que apenas duas amostras das 18 analisadas não obtiveram os $50 \%$ de calcário passante em peneiras de $0,30 \mathrm{~mm}$. Isso demonstra que proporção superior a $80 \%$ deve reagir totalmente no solo, em um período de três meses.

Valores de $\mathrm{CaO}+\mathrm{MgO}$, PN e PRNT mostraram-se baixos em relação aos exigidos para comercialização. Isso demonstra que o material estudado não é recomendado para fins industriais. No entanto, seu aproveitamento por agricultores familiares locais podem minimizar gastos com adubos químicos na correção da acidez dos solos.

\section{AGRADECIMENTOS}

À Fundação de Amparo à Pesquisa do Estado do Acre (FAPAC) pela concessão de Bolsa de Iniciação Científica (ao primeiro e terceiro autor) por meio do Edital 013/2014 FAPAC/CNPq, e à EMBRAPA/AC, pela disponibilidade do uso do laboratório de solos para as atividades de pesquisas.

\section{REFERÊNCIAS}

ACRE (Estado). Programa Estadual de Zoneamento Ecológico-Econômico do Estado do Acre.

Zoneamento Ecológico-Econômico do Acre Fase II: documento Síntese - Escala 1:250.000. Rio Branco: SEMA, 2006. 356p.

AMARAL, E.F.; ARAÚJO, E.A.; LANI, J.L.; RODRIGUES. T.E.; OLIVEIRA, H.; MELO, A.W.F.; AMARAL, E.F.; SILVA, J.R.T.; RIBEIRO NETO, M.A.; BARDALES, N.G. Ocorrência e distribuição das principais classes de solos do estado do Acre. In: ANJOS, L. H. C.; SILVA, L. M.; WADT, P. G. S.; LUMBRERAS, J. F.; PEREIRA, M. G (Editores). Guia de Campo da IX Reunião Brasileira de Classificação e Correlação de Solos. 1. ed. Rio Branco: Embrapa/ SBCS, 2013. p. 97-129.

AMARAL, E.F. Caracterização pedológica das unidades regionais do Estado do Acre. Rio Branco: Embrapa Acre, 2000. 15p. (Embrapa Acre. Circular Técnica, 29).

BARDALES, N.G.; RODRIGUES, T.E.; OLIVEIRA, H.; AMARAL, E.F.; ARAÚJO, E.A.; LANI, J.L.; MELO, A.W.F.; AMARAL, E.F. Formação, classificação e distribuição geográfica dos solos do Acre. In: SOUZA, C.M.; ARAUJO, E.A.; MEDEIROS, M.F.S.T.; MAGALHÃES, A.A. (Org.). Recurso

\begin{tabular}{llllll}
\hline Caminhos de Geografia & Uberlândia - MG & v. 19, n. 67 & Set/2018 & p. 338-348 & Página 346
\end{tabular}


naturais: geologia, geomorfologia e solos do Acre. Rio Branco, AC: SEMA, 2010. (Coleção temática do ZEE; v. 2) p. 64-91.

BRASIL. Ministério da Agricultura, Pecuária e Abastecimento. Manual de métodos analíticos oficiais para fertilizantes minerais, orgânicos, organominerais e corretivos. Secretaria de Defesa Agropecuária. Coordenação-Geral de Apoio Laboratorial; Murilo Carlos Muniz Veras (Org.) - Brasília: MAPA/ SDA/CGAL, 2014. 220 p.

CAVALCANTE, L.M. Geologia do Estado do Acre. In: SOUZA, C.M.; ARAUJO, E.A.; MEDEIROS, M.F.S.T.; MAGALHÃES, A.A. (Org.). Recurso naturais: geologia, geomorfologia e solos do Acre. Rio Branco, AC: SEMA, 2010. (Coleção temática do ZEE; v. 2) p. 10-29.

CAJAZEIRAS, C.C.A.; PEREIRA, L.A.C.; NÓBREGA, M.; ADAMY, A. Aspectos hidrogeológicos e gestão das águas. In: ADAMY, A. (Org.). Ministério de Minas e Energia. Geodiversidade do estado do Acre. Programa Geologia do Brasil- Levantamento da Geodiversidade. Porto Velho: CPRM, 2015. p.107-116.

CUNHA, G. O. M.; ALMEIDA, J. A.; BARBOZA, B. B. Relação entre o alumínio extraível com KCl e oxalato de amônio e a mineralogia da fração argila, em solos ácidos brasileiros. Revista Brasileira de Ciência do Solo, Viçosa, v. 38, n. 5, p. 1387-1401, set./out. 2014.

DEUS, A. C. F. Avaliação de eficiência relativa para reatividade em silicatos. 2010. $113 f$. Dissertação (Mestrado em Agronomia) - Faculdade de Ciências Agronômicas, Universidade Estadual Paulista "Júlio de Mesquita Filho". Botucatu, SP, 2010.

KOCHE, A.; HANASHIRO, J.; SANTOS, A.R.; ROMERO, A.M.S.; LAVIGNE, M.; GUIDOLIN, J.A.; ALCARDE, J.C. Análise de corretivos agrícolas São Paulo. ANDA, 1989. 30p.

KRONBERG, B.; BENCHIMOL, R. Aridez no Acre: a história climática de uma região. Ciência Hoje, v.16, n.1, p.44-47, 1993.

KRONBERG, B.I.; BENCHIMOL, R.E. Geochemistry and geocronoly of surficial Acre Basin sediments (Western Amazonia): key information for climate reconstruction. Acta Amazônica, v.22, n.1, p.51-69, 1992. https://doi.org/10.1590/1809-43921992221069

LANI, J. L.; AMARAL, E. F. Diagnóstico Ambiental: Feijó a Mâncio Lima, Acre, Brasil. Rio Branco/AC: SEMA. 2002. 211p.

MAEDA, S.; KURIHARA, C. H.; HERNANI, L. C.; SILVA, W. M. Estudo dos materiais calcários usados como corretivos da acidez do solo em Mato Grosso do Sul. Dourados: EMBRAPA-CPAO, 1996. 22 p. (EMBRAPA-CPAO. Boletim de pesquisa, 1).

MELLO FILHO, C. H. R. Estudo de caracterização e aplicação dos resíduos sólidos gerados na fabricação de precipitado de carbonato de cálcio como corretivo da acidez do solo. 2005. 156p. Dissertação (Mestrado em Engenharia de Materiais) - Universidade Federal de Ouro Preto, Ouro Preto, 2005

NAHASS, S.; SEVERINO, J. 2003. Calcário Agrícola no Brasil. Série Estudos \& Documentos, CETEM/MCT, 2003. Disponível em http://www.cetem.gov.br/publicacao/CETEM_SED_55.pdf, acessado em 20-03-2016.

PRIMAVESI, A.C. Características de corretivos agrícolas. São Carlos: Embrapa Pecuária Sudeste, 2004. 28p. (Embrapa Pecuária Sudeste. Documentos, 37).

QGIS Equipe de desenvolvimento, 2016. QGIS Sistema de Informações Geográficas. Open Source Geospatial Foundation Project. Disponível em <http://www.qgis.org/en/site/> Acesso em 14 de fevereiro de 2016.

QUEIROZ, L.R.; COSTA, F.S.; OLIVEIRA, T.K.; MARINHO, J.T.S. Aspectos da cultura do milho no Estado do Acre. Rio Branco, AC: Embrapa Acre. 2015. 30p. (Embrapa Acre. Documentos, 136).

RODRIGHERO, M.B.; BARTH, G.; CAIRES, E.F. Aplicação superficial de calcário com diferentes teores de magnésio e granulometrias em sistema plantio direto. Revista Brasileira de Ciência do Solo, v. 39, n. 6, p. 1723-1736, 2015. https://doi.org/10.1590/01000683rbcs20150036 
SANTOS, R.D.; SANTOS, H.G.; KER, J.C.; ANJOS, L.H.C.; SHIMIZU, S.H. Manual de descrição e coleta de solo no campo. 7.ed. Viçosa: Sociedade Brasileira de Ciência do Solo, 2015. 102 p.

SCHAEFER, C. E. G. R. Clima e paleoclima do Acre: memórias e cenários da aridez quaternária na Amazônia e implicações pedológicas. In: ANJOS, L. H. C.; SILVA, L. M.; WADT, P. G. S.; LUMBRERAS, J. F.; PEREIRA, M. G (Editores). Guia de Campo da IX Reunião Brasileira de Classificação e Correlação de Solos. 1. ed. Rio Branco: Embrapa / SBCS, 2013. p. 59-80.

VIDAL, F. W.H.; LIMA, M.A.B.; CASTRO, N.F.; FERNANDES, T. W.G. Aplicações industriais dos calcários do Cariri cearense. IN: CONGRESSO BRASILEIRO DE ROCHAS ORNAMENTAIS, 3, 2007, Natal. Anais... Rio de Janeiro: CETEM/MCTI, 2008. p. 243-255.

WADT, P.G.S. Manejo de solos ácidos do Estado do Acre. Rio Branco, AC: Embrapa Acre. 2002. 28 p. (Embrapa Acre. Documentos, 79).

Recebido em: 28/01/2017

Aceito para publicação em: 11/06/2018 